\title{
The surprising course of multiple sclerosis relapse in a patient after SARS-CoV-2 vaccination
}

\author{
Piotr Łagosz ${ }^{1,2}$, Jan Biegus ${ }^{1,2}$, Ewa Gruszka ${ }^{3,4}$, Robert Zymliński ${ }^{1,2}$ \\ 'Institute of Heart Diseases, Wroclaw Medical University, Wrocław, Poland \\ 2Department of Heart Diseases, Wroclaw Medical University, Wrocław, Poland \\ ${ }^{3}$ Clinic of Neurology, University Clinical Hospital, Wroclaw Medical University, Wrocław, Poland \\ ${ }^{4}$ Department of Neurology, Wroclaw Medical University, Wrocław, Poland
}

\author{
Correspondence to: \\ Piotr Łagosz, MD, \\ Department of Heart Diseases, \\ Wroclaw Medical University, \\ Borowska 213, 50-556 Wrocław, \\ Poland, \\ phone: +48717331112, \\ e-mail: plagosz1@gmail.com \\ Copyright by the Author(s), 2022 \\ DOI: 10.33963/KP.a2022.0005 \\ Received: \\ November 28, 2021 \\ Accepted: \\ January 5, 2022 \\ Early publication date: \\ January 5, 2022
}

Multiple sclerosis (MS) is the most common chronic neurological disorder mediated by the excessive immune response with peak morbidity between the ages of 20 and 40 years. MS affects over 2 million people globally. It is characterized by recurrent episodes of inflammation resulting in demyelination and degeneration of neurons, oligodendrocytes, and microglia in the brain and the spinal cord. Patients with MS present a variety of symptoms including fatigue, psychiatric disorders, and more specific alterations determined by the location of the lesion in the nervous system. Some symptoms may be caused by the impact of other diseases on the course of MS, as the burden of some comorbidities in this group of patients is greater than in the general population.

The presented case is a 64-year-old male with a history of MS and no known traditional ischemic heart disease risk factors. The patient, who complained of the feeling of numbness, worsened mobility in the arms, and fatigue, was referred to the Neurology Clinic. He associated his symptoms with the vaccination against SARS-CoV-2 the day before. An initial diagnosis of possible MS relapse or a stroke was made, and the patient was referred to the Emergency Department for further tests. Electrocardiography recorded as a part of standard practice showed changes consistent with ST-elevation myocardial infarction (STEMI) (Figure 1A). Urgent coronary angiography revealed an amputated left anterior descending artery (LAD), significant stenosis of circumflex (Cx) and diagonal artery (Dg), and a chronic total obstruction (CTO) of the right coronary artery (RCA). Intravenous eptifibatide and oral acetylsalicylic acid with ticagrelor were administered. Percutaneous coronary intervention (PCI) on LAD and $\mathrm{Dg}$ was performed ad hoc with implantation of 3 drug-eluting stents (DES) (Figure 1B-D). The patient was qualified for further $\mathrm{PCl}$ after magnetic resonance imaging with an assessment of the viability of the myocardium. Laboratory tests showed increased troponin I, C-reactive protein, and leukocytosis. Echocardiography revealed decreased left ventricular ejection fraction (40\%) and pericardial effusion. Computed tomography of the head revealed a hypodense lesion in the left frontal-parietal area. A relapse of MS was diagnosed and therapy with glucocorticosteroids was initiated. In the following days, the patient's condition continued to improve.

What makes this case particularly interesting is that nothing foreshadowed such a course of events. It is known that patients with MS are at a higher risk of developing coronary artery disease with life expectancy approximately 10 years shorter compared to the general population [1]. It has been proven to increase the risk of death threefold, mostly due to cardiovascular disease, which is clinically manifest as heart failure and ischemic heart disease [2] (Supplementary material). It should be remembered that patients diagnosed with MS may present atypical clinical symptoms or even remain asymptomatic.

What remains unclear in this case is the role of SARS-CoV-2 vaccination. Demonstrating a causal relationship requires longer follow-up, yet there are reports linking immunization with anti-COVID-19 vaccination and episodes of both MS relapse and thrombosis, 


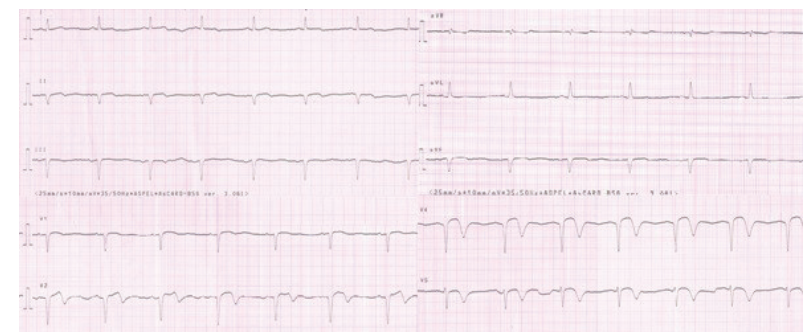

\section{A}
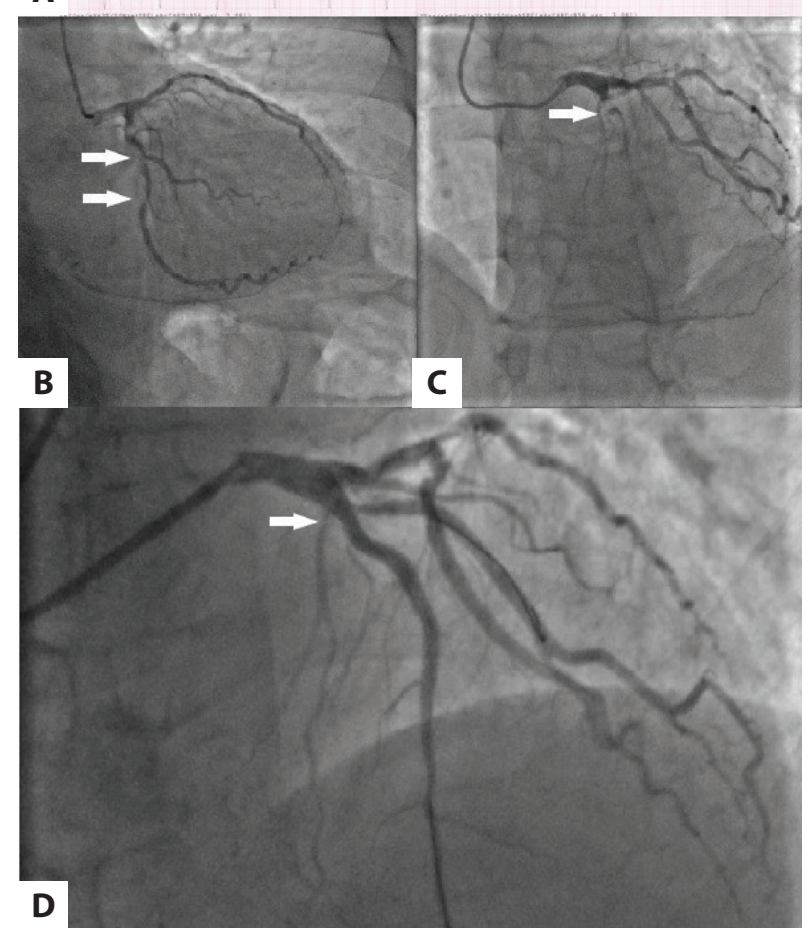

Figure 1. A. The electrocardiograph at admission. Sinus rhythm, left axis deviation, left anterior hemiblock, QS complex in leads II, V1-V4, ST-segment elevation in leads V1-V4, and inverted T waves in leads V1-V6. B. Coronary angiography showing stenosis in CX. C. Coronary angiography showing stenosis in $\mathrm{LAD}$ and $\mathrm{Dg}$. D. Effects of primary PCl on LAD and Dg

Abbreviations: $C x$, circumflex artery; $D g$, diagonal artery; LAD, left anterior descending artery; $\mathrm{PCl}$, percutaneous coronary intervention which could be one of the factors leading to STEMI in this case $[3,4]$. Recently, articles on post-vaccination myocarditis have been published [5]. Postulated mechanisms that could lead to thrombotic manifestation are immune thrombocytopenia induced by vaccine and Kounis syndrome, which is an allergic reaction to a xenobiotic, resulting in the release of i.a. pro-inflammatory cytokines and platelet-activating factor and, potentially, leading to coronary artery spasm and thrombotic events.

\section{Supplementary material}

Supplementary material is available at https://journals. viamedica.pl/kardiologia_polska.

\section{Article information}

Conflict of interest: None declared.

Open access: This article is available in open access under Creative Common Attribution-Non-Commercial-No Derivatives 4.0 International (CC BY-NC-ND 4.0) license, allowing to download articles and share them with others as long as they credit the authors and the publisher, but without permission to change them in any way or use them commercially. For commercial use, please contact the journal office at kardiologiapolska@ptkardio.pl.

\section{REFERENCES}

1. ScalfariA,KnappertzV,CutterG,etal.Mortalityin patients with multiplesclerosis. Neurology.2013;81(2): 184-192, doi:10.1212/WNL.0b013e31829a3388, indexed in Pubmed: 23836941.

2. Lalmohamed A, Bazelier MT, Van Staa TP, et al. Causes of death in patients with multiple sclerosis and matched referent subjects: a population-based cohort study. Eur J Neurol. 2012; 19(7): 1007-1014, doi: 10.1111/j.14681331.2012.03668.x, indexed in Pubmed: 22353360.

3. Maniscalco GT, Manzo V, Di Battista ME, et al. Severe multiple sclerosis relapse after COVID-19 vaccination: a case report. Front Neurol. 2021; 12: 721502, doi: 10.3389/fneur.2021.721502, indexed in Pubmed: 34447349.

4. Srinivasan KN, Sathyamurthy I, Neelagandan M. Relation between COVID-19 vaccination and myocardial infarction - Casual or coincidental? IHJ Cardiovasc Case Reports. 2021; 5(2): 71-74, doi: 10.1016/j. ihjccr.2021.05.003.

5. Sokolska JM, Kurcz J, Kosmala W. Every rose has its thorns - acute myocarditis following COVID-19 vaccination. Kardiol Pol. 2021; 79(10): 1153-1154, doi: 10.33963/KP.a2021.0075, indexed in Pubmed: 34331307. 